\title{
Dynamics of a Flywheel Energy Storage System Supporting a Wind Turbine Generator in a Microgrid
}

DOI 10.1515/ijeeps-2015-0128

Received August 1, 2015; revised October 22, 2015;

accepted November 6, 2015

\begin{abstract}
Integration of an induction machine based flywheel energy storage system with a wind energy conversion system is implemented in this paper. The nonlinear and linearized models of the flywheel are studied, compared and a reduced order model of the same simulated to analyze the influence of the flywheel inertia and control in system response during a wind power change. A quantification of the relation between the inertia of the flywheel and the controller gain is obtained which allows the system to be considered as a reduced order model that is more controllable in nature. A microgrid setup comprising of the flywheel energy storage system, a two mass model of a DFIG based wind turbine generator and a reduced order model of a diesel generator is utilized to analyse the microgrid dynamics accurately in the event of frequency variations arising due to wind power change. The response of the microgrid with and without the flywheel is studied.
\end{abstract}

Keywords: flywheel, microgrid, wind turbine generator

\section{Introduction}

Energy storage is an empowering technology that can respond to improve the operational capability of the grid with increasing penetration of renewable power. The ability of storage in frequency regulation, preventing transmission congestion and facilitating ancillary services from renewable power generation has been deliberated in many related works. Whether the storage is required for a long term or short term application and whether it requires to charge and discharge frequently is a decisive factor in choosing a storage device. It also

\footnotetext{
*Corresponding author: Gayathri Nair S, Department of Electrical Engineering, Indian Institute of Technology Delhi, Block II 137, Delhi, New Delhi 110016, India, E-mail: gayathrinairs@gmail.com Nilanjan Senroy, Department of Electrical Engineering, Indian Institute of Technology Delhi, Block II 137, Delhi, New Delhi 110016, India
}

depends on cost, application, efficiency and life time of the device. Out of the reported capacity of $24.6 \mathrm{GW}$ of mixed storage deployed world wide the largest part is played by pumped hydro storage [1]. It is one of the oldest forms of storage but constrained by cost, geographical and environmental impacts and response times. Compressed air energy storage offers backup and seasonal reserves but cease to be efficient with their noise and longer response time than flywheels and batteries. Superconducting magnetic storage has low energy density and is prohibitively costly as are electrochemical capacitors. Many large scale implementations of batteries are in operation, the most matured technology being that of lead-acid batteries. Batteries require regular maintenance and owing to their limited life span also need frequent replacements hence finds limited use in frequent cycling applications.

Frequency regulation in power systems requires response in the time range of seconds to minute. In a system with higher penetration of renewables, where the inertial contribution from conventional generators is negligible and governor action is limited this is the time window where storage with a fast ramp rate and response time of few seconds is beneficial. Unprecedented load changes, black start facility and reactive power support are other requirements that can be met by fast responding storage.

Flywheel energy storage systems (FESS) are fast responsive systems that can follow rapidly changing control signals [2]. Some of their advantages can be enumerated as follows. Their depth of discharge and frequent cycling does not affect its life significantly [3] with the end of life power rating and capacity being the same as that at the beginning. They can operate in a wide range of temperatures in contrast to batteries which require controlled temperature. The speed of the flywheel translates to its state of charge in contrast to the battery where it is unavailable. They also have much higher power densities and higher specific energy which translate to less space requirements and instantaneous charging.

FESS incorporated into the grid for the purpose of power smoothening, voltage sag corrections and frequency regulations have been discussed in refs [4-8]. 
The control topologies used vary from rotor flux oriented control implemented to improve the integration of wind energy, to using fuzzy inference systems [10-12] and torque control of IM based flywheel in refs [13-15]. A flywheel connected to the DC link of an inverter based wind turbine generator is one configuration that has been explored in refs [8-9] and [16-20]. Most of the existing control strategies require accurate measurements and feedback of quantities such as speed which brings about additional investments, and accuracy and maintenance related issues.

In this paper, the application of FESS to frequency regulation of a microgrid facing intermittent wind power is achieved. The control of the FESS is done using an integral controller which helps in regulating speed and therefore the power stored and discharged by the FESS. The relation between the flywheel inertia and its controller gain is studied by small signal stability analysis. This is done to arrive at a suitable controller gain and inertia combination such that the sizing of the FESS can be easily done with respect to the controller used. A reduced order model of the induction machine based FESS is developed and applied to a representative microgrid comprising of a diesel generator and a variable speed wind turbine generator in addition to a frequency dependent load. Section 2 discusses the comparative configurations and different applications where flywheels have been put into use. Sections 3 and 4 details the modelling, control and stability analysis of FESS. Section 5 discusses the structure of the microgrid with details of the reduced order models for the diesel-generator and variable speed WTG. Results and simulation are presented in Section 6. Section 7 is the concluding section.

\section{FESS: comparative designs and applications}

Flywheel classifications based on low speed and high speed can be related to its high power with low discharge time and high energy applications as high speed relates to higher energy stored [21]. Low speed category flywheels with speeds upto $10,000 \mathrm{rpm}$ are heavier flywheels with higher energy content and simple construction. Their power intensive and stationary applications can be scaled using modular arrangements and in a comparison amongst devices, flywheels required are lesser in number [22, 23].

The idling losses which include power conversion system losses and vacuum generator losses are less and comparable in low as well as high speed flywheels [24]. Loss of around $12 \mathrm{~kW}$ or 0.2 to $0.5 \%$ for an $18 \mathrm{MW}$ rated storage caused due to excitation currents drawn by the machine is discussed in Ref. [25]. Flywheels generally have 100,000 full charge and discharge cycles. The speed levels and operating conditions of the flywheel components if kept under critical limits the flywheel can have longer life than the stipulated 20 years. Batteries may appear economically attractive but frequent replacements required offset this advantage in comparison to the flywheel [26].The current, frequency and voltage to be handled by the bidirectional power electronic components decide their ratings which in turn limit the speed range of operation.

The motor-generator system is an important aspect of the flywheel with, permanent magnet synchronous machine (PMSM), brush less dc machines, induction machines (IM), doubly fed Induction machines (DFIM) and switched reluctance machines being the most commonly found drive assemblies. Synchronous machines perform better for constant speed applications. Switched reluctance motors operate with low power factor and are noisy and costly power electronics are needed to control shaft position in addition to danger of de-alignment from path of least reluctance. DFIM's are expensive while PMSM's are generally more sensitive to temperature rise with the danger of being demagnetized. Squirrel cage IM's are controllable, more robust and economical due to their simple construction. They have less weight and size with negligible possibility of out of control operation if it is run under permissible slip.

Application of flywheel in railways in regenerative traction, energy bill management and voltage support and atomic research facilities using flywheels capable of 340 MW in 30 s have been reported in Ref. [27]. An FESS weighing $3,000 \mathrm{~kg}$ rated at $18 \mathrm{MW}$ at $6,000 \mathrm{rpm}$ used in frequency regulation, power quality improvement, and battery life extension and reducing $\mathrm{CO}_{2}$ emissions is discussed in Ref. [25]. An UPS application of rated power for $15 \mathrm{~s}, 1 \mathrm{MW}$ for full $90 \mathrm{~s}$, in data centres and mission critical applications with $300 \mathrm{~kW}$ modules are discussed in refs [28-30]. 200 FESS units employed for frequency regulation and voltage support is discussed in Ref.[31].

High speed flywheels used in high energy applications are costlier due to their constructional improvements such as application of bearings using magnetic levitation, vacuum containers and composite materials with high specific strength. The energy related cost of flywheels varies from $\$ 4,000 / \mathrm{kWh}$ onward and the cost of associated power electronics is rated at around $25 \%$ of the total cost $[24,32]$. It is conclusive that application of a 
utility scale flywheel running at low speeds required to charge or discharge at a certain speed and has the ability to service frequent fluctuating demands is suited to the problem of frequency regulation as discussed in this paper.

\section{Nonlinear FESS model}

Study of induction machines working as FESS has been undertaken before and its suitability to act as the same has been established. This work is undertaken to establish a relation between the inertia of the flywheel and the controller parameters such that the sizing of the FESS is in correlation with the controller behaviour and subsequently able to give a better performance. This involves studying the modelling of the induction machine along with the controller action. The FESS is modelled as a squirrel cage induction machine with high inertia and connected to the electrical network via back-to-back PWM converters coupled via a dc-link capacitor. The machine side converter controls the terminal voltage of the machine (voltage magnitude and frequency), thus behaving like a controlled voltage source. The grid side converter acts as a controlled current source, holding the dc link voltage at its nominal value. The controller, proposed in this paper, acts on the machine side converter causing it to decrease and increase the machine speed. The grid side converter control is not relevant to the context of work in this paper and therefore not discussed. The behaviour of the converters has not been considered as their operational characteristics do not fall in the time frame of the steady state operation of the machine. The machine works as a motor up to the synchronous speed and above synchronous speed as a generator. The modes of operation of the FESS are charging, standby and discharging mode according to the difference between its rotor speed and the synchronous speed.

The power output of the flywheel at the stator terminals is given by eq. (1) and the electrical torque is given by eq. (2) in p.u where $v_{d s}$ and $v_{q s}$ are the stator voltages [p.u.] in a synchronously rotating $d q$ frame of reference. The set of differential equations defining the electrical states of an induction machine are given below as in Ref. [33]

$$
\begin{gathered}
P_{o}=v_{d s} i_{d s}+v_{q s} i_{q s} \\
T_{e}=\frac{e_{d}^{\prime} i_{d s}+e_{q}^{\prime} i_{q s}}{\omega_{s}} \\
\frac{d e_{d}^{\prime}}{d t}=-\frac{1}{T_{0}}\left[e_{d}^{\prime}-\left(X-X^{\prime}\right) i_{q s}\right]+s \omega_{s} e_{q}^{\prime}
\end{gathered}
$$

$$
\begin{gathered}
\frac{d e_{q}{ }^{\prime}}{d t}=-\frac{1}{T_{0}}\left[e_{q}{ }^{\prime}+\left(X-X^{\prime}\right) i_{d s}\right]-s \omega_{s} e_{d}^{\prime} \\
\frac{d i_{d s}}{d t}=\frac{\omega_{s}}{X^{\prime}}\left(-r_{s} i_{d s}+X^{\prime} i_{q s}+e_{d}{ }^{\prime}-v_{d s}+\frac{1}{\omega_{s}} \frac{d e_{q}{ }^{\prime}}{d t}\right) \\
\frac{d i_{q s}}{d t}=\frac{\omega_{s}}{X^{\prime}}\left(-r_{s} i_{q s}-X^{\prime} i_{d s}+e_{q}^{\prime}-v_{q s}-\frac{1}{\omega_{s}} \frac{d e_{d}{ }^{\prime}}{d t}\right)
\end{gathered}
$$

$T_{O}$ is the transient open-circuit time constant, $X$ the opencircuit reactance and $X^{\prime}$ is the short-circuit reactance of the induction machine. $T_{m}$ is the mechanical torque input to the machine. The slip $s$ and $r_{s}$, the stator resistance, are all in p.u. The electromechanical equation governing the unloaded shaft dynamics in actual units $[\mathrm{N}-\mathrm{m}]$ is

$$
J \frac{d \omega_{r}}{d t}=-T_{\text {electrical }}
$$

In per-unit, the shaft equation becomes

$$
J \frac{\omega_{\text {base }}^{2}}{S_{\text {base }}} \frac{d \omega_{r}}{d t}=-T_{e}
$$

where $\omega_{\text {base }}$ is the base angular speed of the machine $[\mathrm{rad} / \mathrm{s}]$, and $S_{\text {base }}$ is the rated capacity of the induction machine [Watts]. $\omega_{r}$ is in p.u. Equations (3) to (6) represent voltage behind transient reactance model of equations and stator currents of the induction machine. The electromechanical eq. (8) completes the fifth order model of the induction machine. $J$ in $\mathrm{kg}-\mathrm{m}^{2}$ is the combined moment of inertia of the flywheel, located on the machine shaft and the machine.

A variation in energy stored, $\Delta E$, in a flywheel of moment of inertia $J \mathrm{~kg}-\mathrm{m}^{2}$, can be quantified as in eq. (9) where $\omega_{s}$ varies from $\omega_{s \min }$ to $\omega_{s \max }$

$$
\Delta E=\frac{1}{2} J\left(\omega_{s \max }{ }^{2}-\omega_{s \min }{ }^{2}\right)
$$

The controller is represented by eq. (10). Here, the change in synchronous frequency $\omega_{s}$ is obtained from the integral of the difference between the reference power and the actual power output of the induction machine given as

$$
\frac{d \omega_{s}}{d t}=-\frac{P_{\text {com }}-P_{o}}{T}
$$

Equations (3)-(6), (8) and (10) constitute the sixth order FESS consisting of five differential equations for the induction machine and one control equation for active power control. The command signal, $P_{\text {com }}$, in eq. (10) is based on the ultimate objective of employing the FESS, whether for frequency regulation or power smoothening from the WTG.

To achieve network frequency regulation $P_{c o m}$ is made proportional to the changes in system frequency. 
For smoothening of the power output of a WTG, $P_{\text {com }}$ should be proportional to the variations in the WTG output with respect to the dispatch power.

Model order reduction enables reducing the complexity of the system and requires less computational time. Reduced order models can give more insight into the effect of critical parameters on the system behaviour and may remove insignificant dynamics from the picture. In large scale power systems transient stability studies reduced order modelling can be used provided it is compared with the performance of the detailed model. In the work presented, the comparison between the fifth and third order model has been done and is seen that the performance in both cases are almost the same. Inorder to achieve simplicity and better controllability the third order model has been used. The FESS dynamic performance i.e. the manner in which it responds to a change in the $P_{c o m}$ and thus makes power available depends on the flywheel shaft inertia and the controller gain. In order to analyse the impact of these two parameters, the complexity of eqs (3)-(8) can be reduced to a third order model by neglecting the stator transients in eqs (5) and (6). A comparison between the fifth order, third order and the transfer function model response of the FESS is shown in Figure 1. The response being very similar with little difference, it can be surmised that reducing the order of the machine does not alter the system dynamics significantly. Figure 1 shows the flywheel response to a step

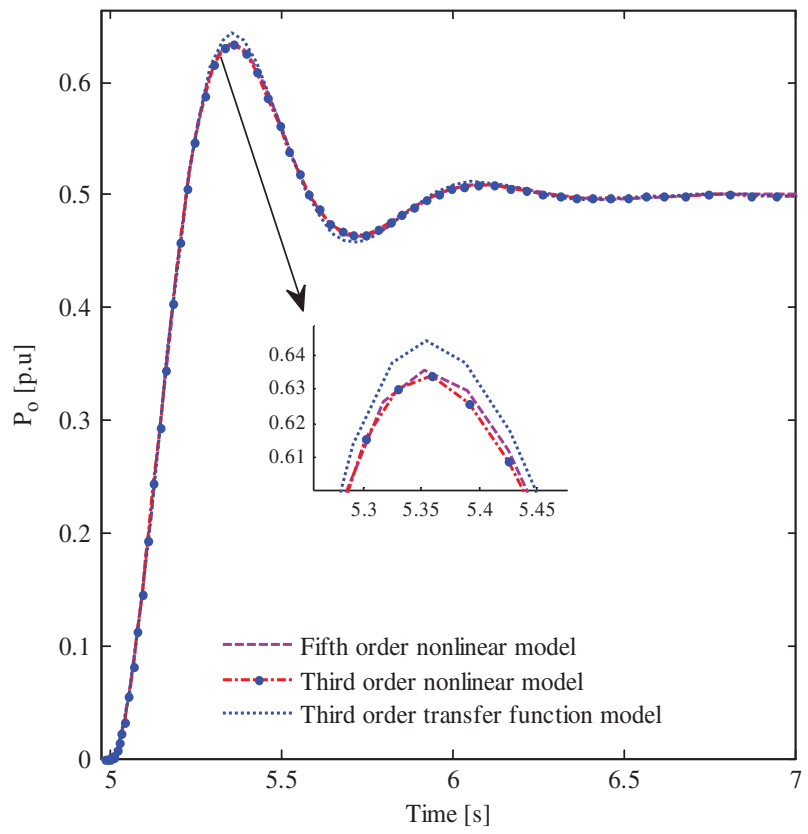

Figure 1: Step response of the flywheel fifth order and third order nonlinear and transfer function for $\mathrm{J}=3,38,097 \mathrm{~kg}-\mathrm{m}^{2}$ and $\mathrm{T}=10$, to a $P_{\text {com }}=0.5$ p.u. change in $P_{\text {com }}$ shown for a 4 MW FESS with a base speed of 3,000 rpm and moment of inertia of 3,38,097 kg-m².

\section{FESS - small signal analysis}

Small signal stability analysis of the third order FESS model, with the addition of the control equation, using eqs (3), (4), (8) and (10) is done. The model of the FESS is linearized around an initial operating point that of rated voltage at 1 p.u and rated speed at 1 p.u.

$$
\begin{aligned}
& \Delta \dot{X}=A \Delta X+B \Delta U \\
& \Delta Y=C \Delta X+D \Delta U
\end{aligned}
$$

Equation (13) is the state space representation of any nonlinear system giving valuable information regarding the overall system dynamics and here the state vector considered is $\Delta X=\left[\Delta e_{d}^{\prime}, e_{q}^{\prime}, \omega_{r}, \omega_{s}\right]^{\prime}$. The input vector being $\Delta U=\Delta P_{\text {com }}$ and the output vector $\Delta Y=\Delta P_{0}$.

For a particular value of $J$ and $T$, Table 1 gives the participation of the FESS state variables in the single oscillatory mode of frequency $2.069 \mathrm{~Hz}$. It is clear that the participation of $e_{d}^{\prime}$ and $\omega_{s}$ are the highest in the oscillatory mode where as that of $e_{q}^{\prime}$ and $\omega_{r}$ is the lowest. This indicates that the FESS behaves like a second order system for the selected values of the shaft inertia, $J$, and controller gain, $T$. However, this is not always the case as the pattern of participation changes considerably for different values of moment of inertia and controller gain. The aim of this work is to identify the best combination of $J$ and $T$ for which the FESS can be treated as a more controllable second order system.

Table 1: Normalised participation factors of state variables in oscillatory $2.069 \mathrm{~Hz}$ mode.

\begin{tabular}{lr}
\hline State & Normalized participation factor \\
\hline$e_{d^{\prime}}$ & 1.0000 \\
$e_{q}{ }^{\prime}$ & 0.0002 \\
$\omega_{r}$ & 0.0025 \\
$\omega_{s}$ & 0.9974 \\
\hline
\end{tabular}

The participation of $e_{d}^{\prime}$ and $e_{q}^{\prime}$ in the oscillatory mode remains unchanged at the values shown in Table I for increasing values of $J$ and $T$, while the participation of $\omega_{\mathrm{s}}$ increases from a very low value to near unity and that of $\omega_{\mathrm{r}}$ approaches zero from unity. This indicates that the system can further be approximated as a second order system with more controllability. With the increase in 


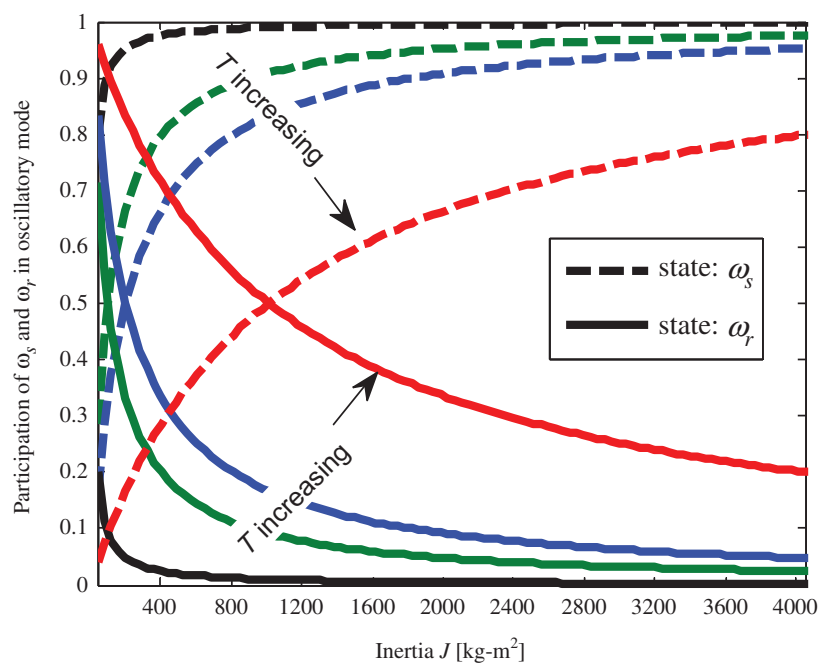

Figure 2: Variation in normalized participation factors of $\omega_{s}$ and $\omega_{r}$ with variation in $J$ and $T$.

$\mathrm{T}$ and $\mathrm{J}$, the transition of the system from being a higher order to a second order follows a pattern. Figure 2 shows the variation of participation (normalised) for varying values of $J$ and $T$. The participation of $\omega_{\mathrm{s}}$ and $\omega_{\mathrm{r}}$ traces a curve whose knee point indicates the transition of the system from higher order to that of second order and vice-versa.

In Figure 2, as the value of controller gain, $\mathrm{T}$ increases the knee point moves towards the right and the choice of combination pairs of inertia and controller gains for which the system can be approximated as a second order becomes lesser. For lighter machines i. e. low moment of inertia the value of $\mathrm{T}$ must be kept small to ensure the FESS behaves like a second order system. For heavier flywheels, relatively larger values of $\mathrm{T}$ may be selected without compromising on the second order character of the FESS.

In Figure 3 the moment of inertia of the flywheel was varied between $\{338,3,380,33,804,338,040\} \mathrm{kg}-\mathrm{m}^{2}$. For low values of $T$, the system generally behaves like a second order system, with a small rise time and a controllable overshoot. However, as the value of $T$ increases, the higher order character of the FESS dominates in lighter flywheel systems. Thus, for flywheel inertia of $338 \mathrm{~kg}-\mathrm{m}^{2}$ and a controller gain of 100, the FESS is unable to follow the command to increase power output to $0.5 \mathrm{p}$. u. Whereas for a heavy flywheel inertia (say 338040), a controller gain of 100 makes the FESS sluggish where as a gain value of less than 49.5 will give a better tracking of power command.

Larger value of $J$ results in larger size and cost which has to be optimized keeping with mechanical
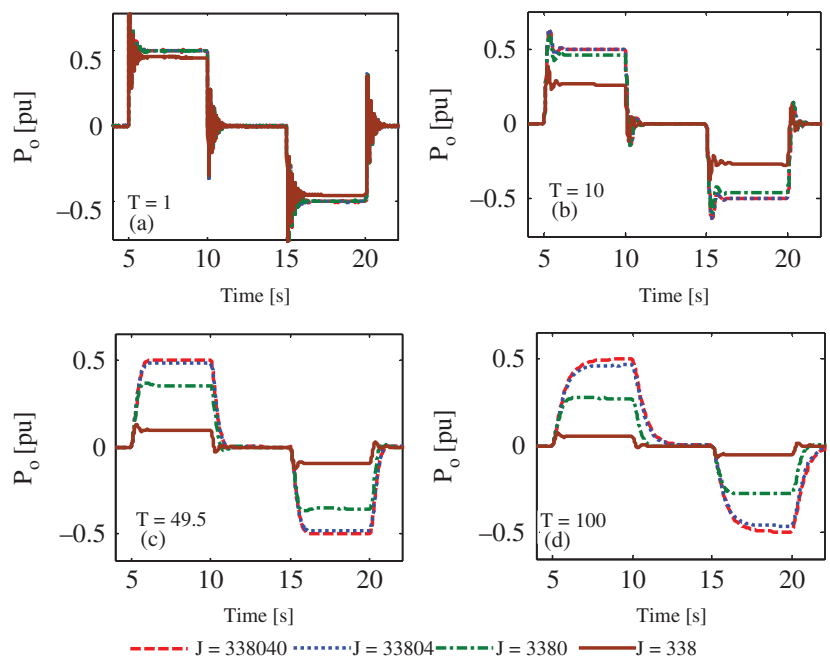

Figure 3: Comparison of the FESS ability to change power output to 0.5 p.u. for different values of $J$ and $T$ in both motoring and generating mode.

constraints. Varying the value of $J$ with a low value of $T$ does not change the steady state error. Aiming at adequate damping with faster rise time and zero steady state error and minimum overshoot, the best possible option will be to keep the $J$ value, as small as system requirements permit, with a $T$ that allows achieving the above conditions. This work serves to identify a closed area within which the value of the controller gain must be for a certain value of inertia.

The incremental transfer function given in eq. (14), is obtained from the linearization of the induction machine and control equations and the transfer function is obtained between the change in power input and the power output of the machine. This linear model has been used to plot the system dynamic characteristics and approximates the system dynamics satisfactorily as seen from Figure 1.

$$
\begin{aligned}
\Delta P_{o}=\frac{-0.000144 J s^{3}+16.02 J S^{2}+(111.78 J-0.7518) s-5.247}{} & 0.0177 J T s^{4}+(0.247 J T-0.000114 J) s^{3} \\
& +(16.02 J+451.4 T+0.863 J T) s^{2} \\
& +(111.78 J+3149 T-0.752) s-5.247 \Delta P_{e}
\end{aligned}
$$

Straightforward application of final value theorem to eq. (14) yields unity, which is the objective of the controller. However, closer scrutiny reveals that achieving zero steady-state error is related to the coefficients of the $s$ and higher order terms in the numerator and denominator of eq. (14). Theoretically, the final value of (14) is independent of both $J$ and $T$. In practice, the coefficients of $s$ in the numerator and the denominator are much higher in magnitude than the constant terms, thereby 
raising the possibility of neglecting them while applying the final value theorem. In that case, the final value of the transfer function (14) is reduced from 1 by a factor proportional to $3149 T /(111.78 J-0.7518)$ or simply $T / J$.

Essentially, the sluggishness of the system becomes more pronounced as the ratio of $T / J$ increases in magnitude. Inorder to make a suitable choice of flywheel the above ratio can be kept as low as possible. It is seen that by having a better understanding of inertia and gain combinations and using the above relation the sizing of the flywheel and controller design is possible.

It can be seen that the slip variation for large change in power output in both motoring and generation mode of the FESS, as shown in Figure 4, are very much within permissible limits indicating that even for a large change in power output the speed variation of the induction machine is within permissible limits and capable of following the power command without fail. This is possible without much variation in the current ratings of the machine and causing stressful operation of the generator and power electronic components.
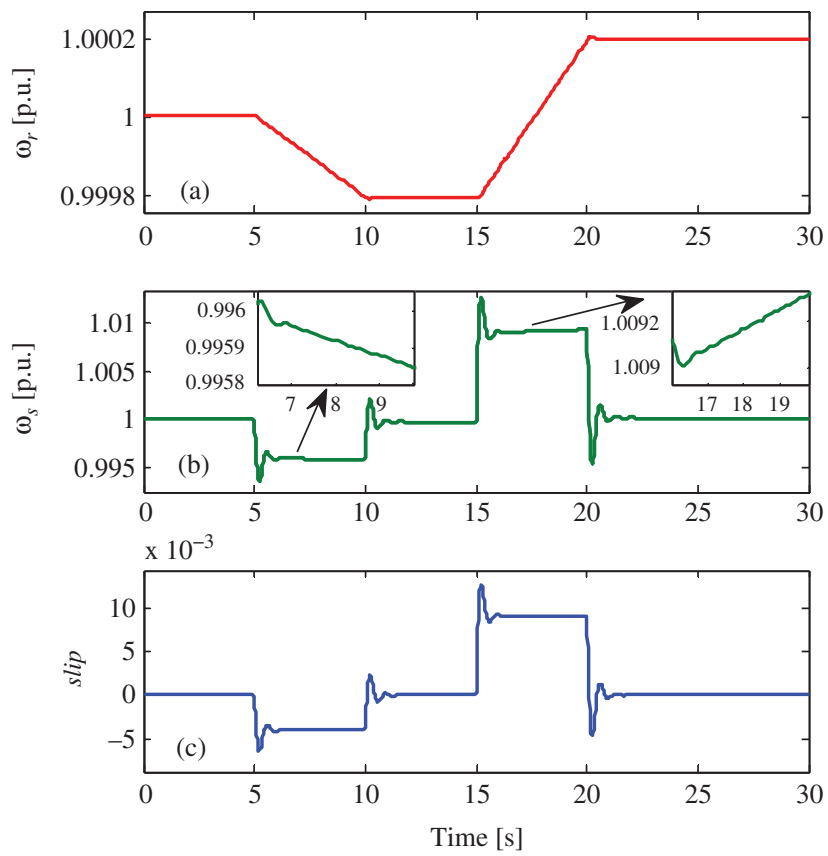

Figure 4: FESS speed and slip characteristics for 0.5 p.u. change in motoring mode and 1.0 p.u. change in generation mode (a) rotor speed (b) synchronous speed (c) slip.

\section{Microgrid structure}

The idea of exploring the microgrid behavior is to analyze how to capitalize the contribution of its controllable and uncontrollable sources in frequency regulation. The microgrid structure considered comprises of a variable speed WTG system, a diesel generator and a FESS working conjointly to provide frequency regulation. The 1.5 MW WTG is controlled to work at maximum power point tracking (MPPT) condition. A 5 MVA synchronous machine based diesel generator is considered, alongwith the 4 MW FESS. The system base is selected to be 5 MVA and all dynamic models are converted to their p.u. values on this base. Since the microgrid, in recent times, are designed to include renewable sources with the diesel generator playing a more or less emergency ramping up and ramping down role, the importance of the FESS is tested here for frequency regulation. The purpose is to avoid the frequent ramping up and down of the diesel generator. The FESS can be utilised to smoothen the power output of the microgrid when accurately sized to do so. The load frequency model of rotating mass and load is taken with inertia constant $\mathrm{H}$ as $5 \mathrm{~s}$ and load damping constant as 0.8 . The microgrid set up considered is shown in Figure 5.

\subsection{Diesel generator model}

A lower order incremental model of the diesel generator and prime mover adequately representing the overall inertia including the actuator time and engine dead time is chosen $[34,35]$ where the governor droop control and an integral controller for secondary frequency response is part of the model.The input to the diesel generator is the incremental change in network frequency $\Delta f$. The representation of the inherent time delays, in a diesel engine, makes this model sufficiently accurate for load-frequency control studies. The droop value, $1 / R$, a measure of the change in power output with respect to change in frequency, is fixed at $6 \%$ and the inertia constant of the thermal generator is taken as $5 \mathrm{~s}$ on the system base. The integral control gain which helps to bring back the frequency to nominal value is taken as 7. The governor time constant is taken as $0.1 \mathrm{~s}$. The dynamics of the engine is modeled with a time delay of $0.25 s$.

\subsection{Wind turbine model}

Transfer function modelling is essential in studying the behaviour of variable speed wind turbines in load frequency control studies. The work done here is to evaluate the effect of wind speed variations on the power output variations of the WTG. A reduced order modelling of the 


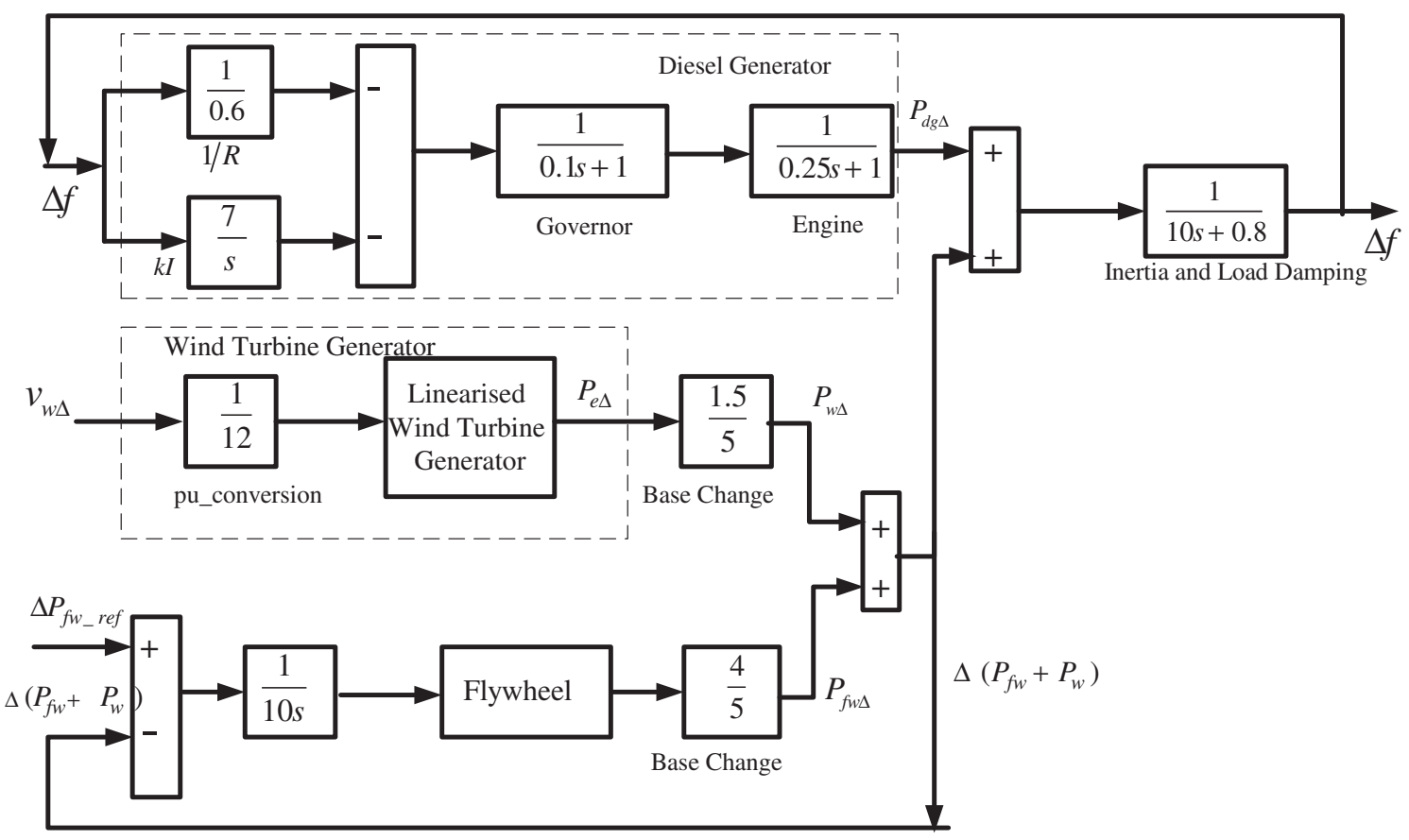

Figure 5: Microgrid.

DFIG to understand its electromechanical dynamics has been done in refs $[36,37]$ which considers both single mass and two mass systems which re sufficiently accurate representations in the time frame of study.

The third order model of the drive train dynamics in which the two mass representation of the shaft is used in the model ie the low speed shaft is represented and the high speed shaft and the gear box are assumed to be infinitely stiff as another mass. The two mass representations recognize the two speeds of the system ie the electric system speed and the mechanical speed of the turbine rotor which are significantly different. Single mass representation of the shaft in the case of wind turbine generators will lead to a more conservative approach in protection settings. The post fault response of a system represented using single-mass and two-mass shows difference of amplitudes and phase in speed and power oscillations.

On similar lines, a two mass model of the WTG, operating at MPPT condition, is considered in this paper. The eqs (15)-(17) is an accurate representation of the two mass drive train model, consisting of a high speed and a low speed shaft and neglecting the stator and rotor side converter dynamics [36-38].

$$
\begin{gathered}
\frac{d \omega_{t}}{d t}=\frac{P_{t u r b}}{2 H_{t} \omega_{t}}-\frac{K_{s} \theta_{t w}}{2 H_{t}} \\
\frac{d \omega}{d t}=\frac{K_{s} \theta_{t w}}{2 H_{g}}-\frac{T_{e}}{2 H_{g}}
\end{gathered}
$$

$$
\frac{d \theta_{t w}}{d t}=\omega_{o}\left(\omega_{t}-\omega\right)
$$

Here $\omega_{t}$ is the angular speed of the turbine, $\omega$ the speed of the generator rotor and $\omega_{o}$ the system frequency all in p.u. $\theta_{t w}$ is the shaft twist angle in p.u. where the shaft damping is neglected. $P_{t u r b}$ is the turbine power generated at a wind speed $v_{w} \mathrm{~m} / \mathrm{s}$ and given as in eq. (18) where $\rho$ is the density of air in $\mathrm{kg} / \mathrm{m}^{3}$ and $A$ is the area swept by the turbine blades in $\mathrm{m}^{2}$.

The value of the power coefficient of the wind turbine $C_{p}$, is a factor of the tip speed ratio $\lambda$ and pitch angle $\beta$. The tip speed ratio is given by

$$
\lambda_{p u}=\frac{\omega_{t-p u}}{v_{w-p u}}
$$

The pitch control has not been considered, as the behaviour of the system with wind power change is more important for this work than the range of wind speed where the pitch control is required to be active. With an inactive pitch angle control, $C_{p}$ relies on only $\lambda$ and only the change in tip speed ratio will be reflected on the value of $C_{p}$. Operation under MPPT control indirectly requires that the tip speed ratio is at its optimum value of 1 p.u. this means $C_{p}$ is at its optimum value of 1 p.u. The change in with respect to will be a constant as it is calculated with respect to the reference value of and is taken as the constant $k_{c p}$. The value of maximum power output at base wind speed is $k_{p}$ given by eq. (20) and is calculated as 0.73 for a base wind speed $v_{w \text {-base }}$ of $12 \mathrm{~m} / \mathrm{s}$. 


$$
\begin{gathered}
k_{p}=\frac{\rho A C_{\text {pnom }} v_{w-\text { base }}^{3}}{2 P_{\text {base }}} \\
T_{e}=k_{p} \omega^{2} \\
P_{\text {turb-pu }}=k_{p} C_{p-p u} v_{w-p u}^{3}
\end{gathered}
$$

The generator torque $T_{e}$ and $P_{t u r b}$, the turbine power are calculated at MPPT in p.u. by eqs (21) and (22). The linearization of the two mass WTG done by following the steps as in Section IV and the model is represented in the state space form as below in eq. (23). This transfer function model is used to represent the DFIG model in the analysis.

$$
\begin{aligned}
{\left[\begin{array}{c}
\dot{\omega}_{t} \\
\dot{\omega} \\
\dot{\theta}_{t w}
\end{array}\right]=} & {\left[\begin{array}{ccc}
\left(\frac{k_{p} k_{c p} v_{w o}^{2}}{\omega_{t o}}-\frac{k_{p} C_{p o} v_{w o}^{3}}{\omega_{t o}^{2}}\right) \frac{1}{2 H_{t}} & 0 & \frac{-K_{s}}{2 H_{t}} \\
0 & -\frac{k_{p} \omega_{o}}{H_{g}} & \frac{K_{s}}{2 H_{g}} \\
\omega_{o} & -\omega_{o} & 0
\end{array}\right] } \\
& {\left[\begin{array}{c}
\omega_{t \Delta} \\
\omega_{\Delta} \\
\theta_{t w \Delta}
\end{array}\right]+\left[\begin{array}{c}
\frac{v_{w o}^{2}}{2 H_{t} \omega_{t o}}\left(3 k_{p} C_{p o}-k_{p} k_{c p} \lambda_{r e f}\right) \\
0 \\
0
\end{array}\right]\left[v_{w \Delta}\right] }
\end{aligned}
$$

The $\mathrm{B}$ matrix gives the relation between the change in electrical power output to change in wind speed and the C matrix is given below in eq. (24).

$$
P_{e \Delta}=\left[\begin{array}{lll}
0 & 3 k_{p} \omega_{o}^{2} & 0
\end{array}\right]\left[\begin{array}{c}
\omega_{t \Delta} \\
\omega_{\Delta} \\
\theta_{t w \Delta}
\end{array}\right]
$$

$H_{t}$ and $H_{g}[\mathrm{~s}]$ are the turbine and generator inertia and $K_{s}$ the shaft stiffness in p.u. torque per radian and given in appendix. The inertia constants are converted from the actual values to system base of 5 MVA. The initial values of the states $\omega_{t o}, \omega_{o}$ and $\theta_{t w o}$ and $v_{w o}$ are the nominal values. This representation of the rotor dynamics along with the correctly detailed aerodynamic model of the wind turbine can emulate the behavior of a variable speed WTG. The power output is also converted to the system base of 5 MVA. The DFIG parameters are given in the appendix.

A near accurate representation of the wind speed variation is assumed by taking the Autoregressive Moving Average model (ARMA) time series representation as in refs [34 and 39]. The ARMA model relates the present wind speed to that of the previous hours and one such real model has been taken to model the wind speed and study the response of the system under fast realistic variations.

\subsection{Flywheel representation}

In the case of a flywheel single mass representation is used as there is no gearbox between the two inertial mass unlike the wind turbine generator drive train where the low speed shaft is connected via the gear box to the high speed shaft. The flywheel is modeled as an additional mass on the induction machine on a shaft and having infinite stiffness. This is considered as a partially integrated system as compared to a highly integrated system where the flywheel and motor are one and the same component and non-integrated system where the two are housed in separate housings [40].

The flywheel responds completely towards the variation in wind power as shown in the results without any additional storage device adopted. In turn it caters for large power charging and discharging which can only be catered for by a large inertial contribution. The inertia of the machine affects the response to power changes as is also evident from the results presented. A rating of the machine was thus chosen so as to corroborate with the inertia chosen. The size of the machine with a large inertia, appended to act as flywheel, requires higher rating of the machine so that the speed variations, due to it acting in the flux weakening mode, current flow and torque variations in the machine are within limits. The size is also in anticipation of the vastly varying nature of wind power. This paper concentrates on the technical aspects of the flywheel dynamics and the problem of sizing of the same has been done in a later work.

The microgrid behaviour when subjected to change in wind speed and the corresponding change in frequency is analysed for different FESS parameter $(J$ and $T)$ specifications. The transfer function of (14) was used to represent the FESS, with the flywheel inertia converted to the system base of 5 MVA.

\section{Simulation and results}

The microgrid dynamics studied here basically concentrates on the change in system frequency when the WTG experiences a change in wind speed. The inclusion of the FESS in the microgrid is to understand how it helps alleviate the microgrid from stress under wind induced variations in the WTG output power. The wind profile variation considered is only representative of the actual profile faced by the WTG's and the arrangement can work in real time also. 
The total power output of the WTG and the FESS was compared with a reference $\Delta P_{f} w_{\text {ref }}$ and the integral of error used as the flywheel $P_{\text {com }}$. An integral time constant of 10 was found ideal, after various trial runs. A step change in wind speed from rated speed of $12 \mathrm{~m} / \mathrm{s}$ by $0.5 \mathrm{~m} / \mathrm{s}$ at $25 \mathrm{~s}$ and back at $75 \mathrm{~s}$ was simulated. When is at 0 p.u it signifies that the total output of the WTG $\Delta P_{f} w_{r e f}$ and FESS should not deviate from its initial operating value, despite a wind speed change as shown in Figure 6.

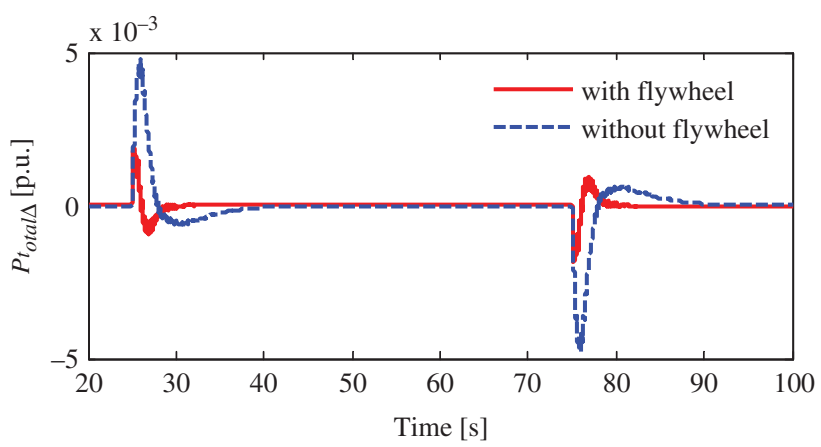

Figure 6: Change in total power $P_{\text {total }}$ [p.u.] with wind speed change at $25 \mathrm{~s}$ and $75 \mathrm{~s}$.

Comparison shows the effect of having the flywheel in the system and how it helps to reduce the change in total power from the microgrid. The system frequency dynamics for the microgrid is shown in Figure 7 where
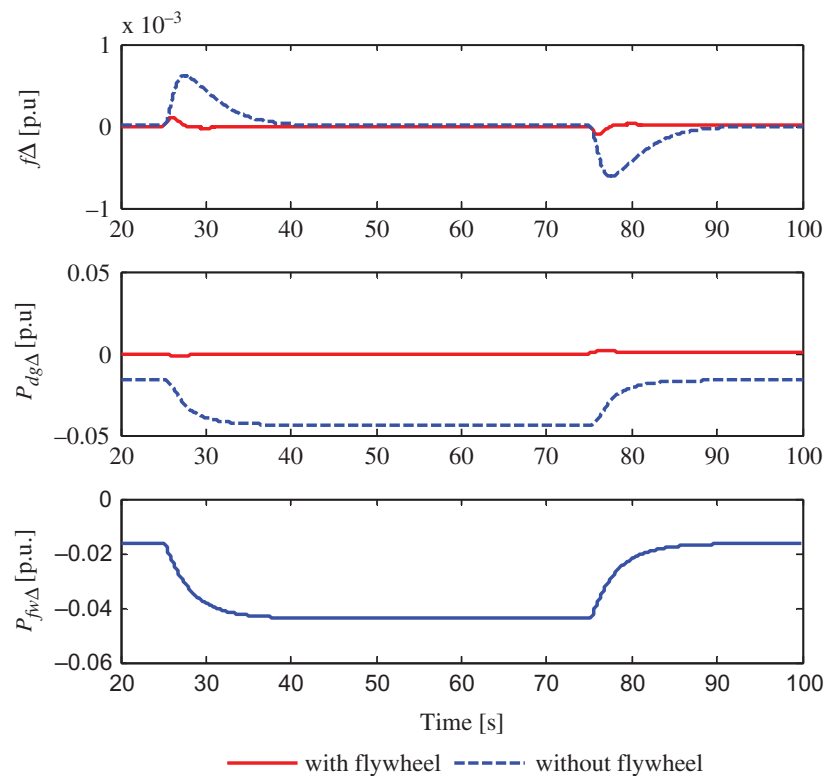

Figure 7: Response to a step increase in wind speed of $0.5 \mathrm{~m} / \mathrm{s}$. (a) change in frequency (b) diesel generator power output (c) flywheel power output. the step change as above was simulated and the resultant frequency deviation compared for a microgrid with and without the FESS. The diesel generator with its integral control loop acts in, bringing the frequency back to nominal after the disturbance. It is observed that both the magnitude and the settling time of the resultant frequency deviation is more in the case of a microgrid without the flywheel. The addition of an FESS to the microgrid improves the system frequency response to the wind speed change and reduces the response required from the diesel generator.
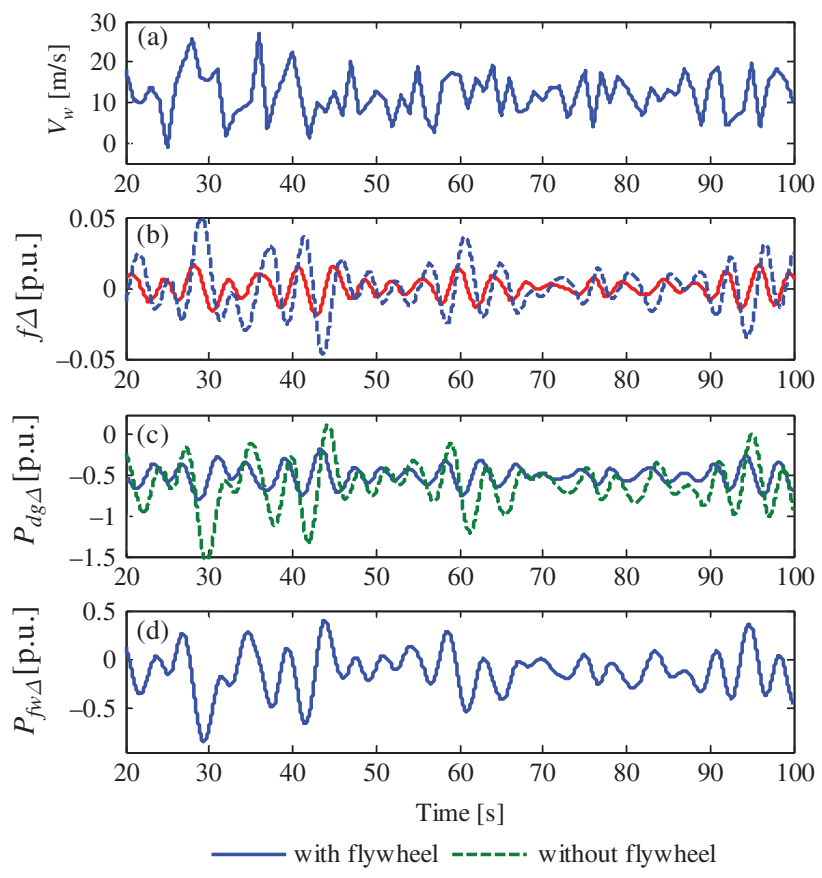

Figure 8: Results for the ARMA wind profile (a) ARMA wind model (b) change in frequency (c) Diesel generator power output (d) Flywheel power output.

The results for the ARMA model wind profile is given in Figure 8 where the variation in wind is in the range from near zero value to above $15 \mathrm{~m} / \mathrm{s}$. With the $\Delta P_{f w_{-} r e f}$ changed to 0.5 p.u. the results show the flywheel capability to act.

The presence of the flywheel reduces the frequency deviation and limits the power output expected from the diesel generator and the network frequency response is considerably affected by the FESS parameters, as shown in Figure 9 where variation in frequency for changes in wind speed projected for varying values of $J$ and $T$ are shown. 

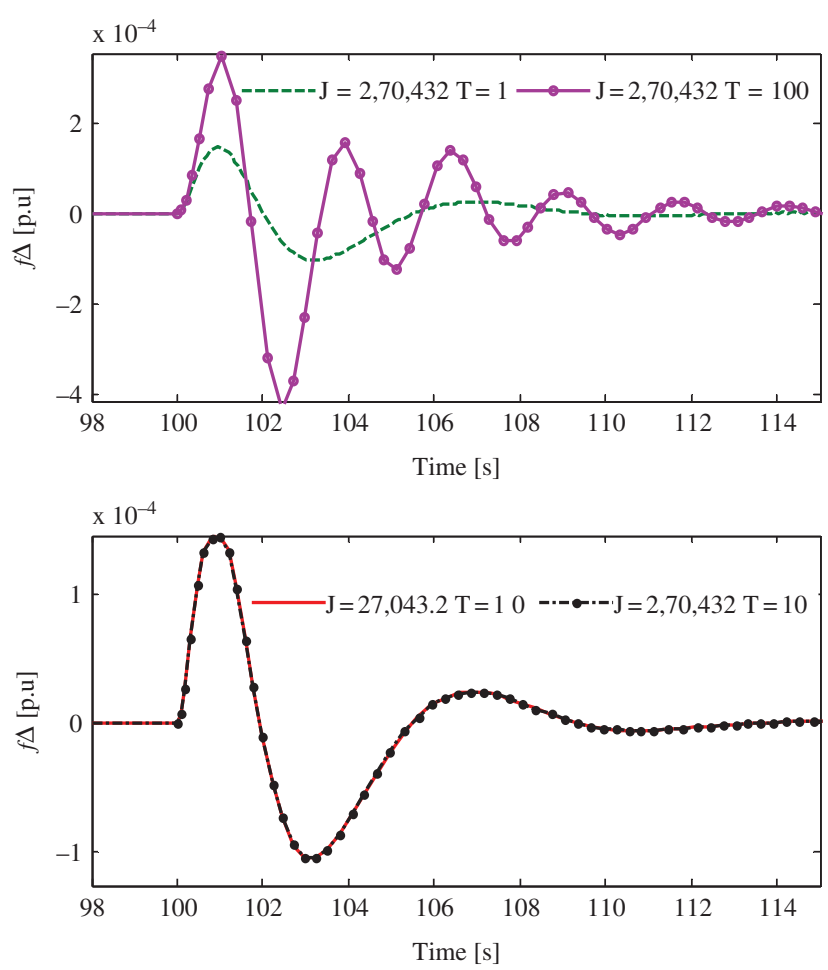

Figure 9: The variation in frequency for changes in wind speed projected for varying values of $J$ and $T$ in motoring and generating modes as the flywheel power varies between +0.5 p.u. to -0.75 p.u. to cover for the wind power variation.

\section{Conclusion}

In this paper, an in-depth analysis of an induction machine based flywheel system is carried out, with the proposed integral control strategy. Starting with a nonlinear differential equation based dynamic model, the FESS was linearized and using eigenvalues and statemode participation patterns a relation between the controller parameter and the flywheel inertia derived to make a proper choice of flywheel. It is observed that the flywheel is generally more controllable with a certain combination of inertia and controller gain. A generic transfer function model of the FESS was also derived, and applied to a typical load frequency control problem in a microgrid consisting of a wind turbine and a diesel generator. The implication of various combinations of flywheel inertia and the FESS controller gain on the microgrid frequency response to a wind variation in the microgrid was also analysed. It is concluded that the ratio of inertia to gain plays an important role in choosing an optimal size of flywheel. The combined analysis of the wind turbine generator, diesel generator and the
FESS using the model derived in this paper proves efficient in regulation of frequency. The system topology discussed with FESS as a storage element shows clearly that the addition of the FESS to the microgrid improves the dynamic performance of the system and in turn improves the efficiency of the other sources connected in it. This work can be extended to study a wind farm and a larger microgrid subjected to varying disturbance scenarios.

\section{Appendix}

Voltage $=1.5 \mathrm{kV}$, Diesel Generator Parameters

Rated Power $=5 \mathrm{MW}$

DFIG Parameters:

Rated Power $=1.5 \mathrm{MW}$, Nominal Speed $=1,500 \mathrm{rpm}$; Rated $/$ Base wind speed $=12 \mathrm{~m} / \mathrm{s}$

$C_{\text {pnom }}=0.48$

$\lambda_{\text {ref }}=1$

$\lambda_{\text {nom }}=8.1$

$k_{c p}=0.0771$

$H_{t}=2.5 \mathrm{~s}$

$H_{g}=0.75 \mathrm{~s}$

$K_{s}=2.332$ p.u. $/ \mathrm{rad}$

Flywheel Parameters:

Rated power $=$ MW,

$L_{s}=0.1614 \mathrm{pu}$

$L_{m}=3.1942 \mathrm{pu}$

$L_{r}=0.1614 \mathrm{pu}$

$R_{S}=0.0067 \mathrm{pu}$

$R_{r}=0.007 \mathrm{pu}$

Nominal Speed $=3,000 \mathrm{rpm}$;

\section{References}

1. Gyuk I, Johnson M, Vetrano J, Lynn K, Parks W, Handa R, Kannberg L, Hearne S, Waldrip K, Braccio R. Grid Energy Storage U.S. Department of Energy; Dec 2013.

2. Mears L, Gotschall H, Kamath H. EPRI-DOE Handbook of energy storage for transmission and distribution applications. EPRI PEAC Corporation. U.S. Department of Energy. Available at: www.epri.com. Accessed: Dec 2003.

3. Okou R, Sebitosi AB, Khan MA, Barendse P, Pillay P. Design and analysis of an electromechanical battery for rural 
electrification in sub-Saharan Africa. IEEE Trans Energy Conv 2011;26:1198-209.

4. Islam F, Hasanien H, Al-Durra A, Muyeen SM. A new control strategy for smoothing of wind farm output using short-term ahead wind speed prediction and flywheel energy storage system. American Control Conference (ACC), 2012, 3026-3031, 27-29 June 2012.

5. Lee H, Shin BY, Han S, Jung S, Park B, Jang G. Compensation for the power fluctuation of the large scale wind farm using hybrid energy storage applications. IEEE Trans Appl Supercond Jun 2012;22: 5701904.

6. Feng J, Gongbao W, Lijun F, Gang W, Zhen X. Applying flywheel energy storage system to integrated power system for power quality and stability enhancement. International Conference on Electrical Machines and Systems (ICEMS), Aug 2011.

7. Greigarn T, Garcia-Sanz M. Control of flywheel energy storage systems for wind farm power fluctuation mitigation. IEEE Energytech, 2011, 1-6, 25-26 May, 2011.

8. Cardenas R, Pena R, Asher G, Clare J. Control strategies for enhanced power smoothing in wind energy systems using a flywheel driven by a vector-controlled induction machine. IEEE Trans Ind Electron 2001;48:625-35.

9. Cardenas R, Pena R, Asher GM, Clare J, Blasco-Gimenez R. Control strategies for power smoothing using a flywheel driven by a sensorless vector-controlled induction machine operating in a wide speed range. IEEE Trans Ind Electron 2004;51: 603-14.

10. Suvire GO, Mercado PE. Combined control of a distribution static synchronous compensator/flywheel energy storage system for wind energy applications. IET Gener Transm Dis 2012;6:483-92.

11. Cimuca GO, Saudemont C, Robyns B, Radulescu MM. control and performance evaluation of a flywheel energy-storage system associated to a variable-speed wind generator. IEEE Trans Ind Electron 2006;53:1074-85.

12. Leclercq L, Robyns B, Grave JM. Control based on fuzzy logic of a flywheel energy storage system associated with wind and diesel generators. Math Comp Simul 2003;63: 271-80.

13. Greigarn T, Garcia-Sanz M. Control of flywheel energy storage systems for wind farm power fluctuation mitigation, IEEE Energy Tech, 2011, 1-6, 25-26 May 2011.

14. Suvire GO, Molina MG, Mercado PE. Improving the integration of wind power generation into ac microgrids using flywheel energy storage. IEEE Trans Smart Grid Dec 2012;3:1945-54.

15. Sun XD, Koh KH, Yu BG, Matsui M. Fuzzy-logic-based $v / f$ control of an induction motor for a dc grid power-levelling system using flywheel energy storage equipment. IEEE Trans Ind Electron 2009;56:3161-8.

16. Ran L, Dawei X, Kirtley JL. Analysis of electromechanical interactions in a flywheel system with a doubly fed induction machine. IEEE Trans Ind Appl 2011;47:1498-506.

17. Ghedamsi K, Aouzellag D, Berkouk EM. Control of wind generator associated to a flywheel energy storage system. Renew Energ 2008;33:2145-56.

18. Wang L, Yu JY, Chen YT. Dynamic stability improvement of an integrated offshore wind and marine-current farm using a flywheel energy-storage system. IET Renew Power Gen 2011;5:387-96.
19. Diaz-Gonzalez F, Bianchi FD, Sumper A, Gomis-Bellmunt 0 . Control of a flywheel energy storage system for power smoothing in wind power plants. IEEE Trans Energy Conv 2014;29:204- 14.

20. Islam F, Al-Durra A, Muyeen SM. Smoothing of wind farm output by prediction and supervisory-control-unit-based fess. IEEE Trans Sustain Energy Oct 2013;4:925-33.

21. Abdel-Khalik AS, Elserougi AA, Massoud AM, Ahmed S. Fault current contribution of medium voltage inverter and doubly-fed induction-machine-based flywheel energy storage system. IEEE Trans Sustain Energy 2013;4:58-67.

22. Hittinger ES. Energy storage on the grid and the short-term variability of wind, Ph.D. dissertation, Eng and Public Policy, Carnegie Mellon Univ., Pittsburgh, PA, Aug, 2012.

23. Carbone R. Energy storage in the emerging era of smart grids. Available at: http://www.intechopen.com. Accessed: Oct 2014.

24. Akhil AA, Huff G, Currier AB, Kaun BC, Rastler DM, Chen SB, et al. DOE /EPRI 2013- Electricity Storage Handbook in Collaboration with NRECA. Sandia National Laboratories, Albuquerque, New Mexico SAND2013-5131, July 2013.

25. Anonymous. Integrating-renewables-into-microgrids. ABB. Available at: http://www.abb.co.in. Accessed: Oct 2014.

26. Anonymous, Flywheel energy storage. federal technology alertA new technology demonstatrion publication U.S-DOE,DOE/EE0286, Sept 2003, Accessed: Oct 2014.

27. Anonymous. Available at: http://www.energystorageexchange. org. Accessed: Oct 2014.

28. Strasik M, Hull JR, Mittleider JA, Gonder JF, Johnson PE, McCrary KE, Mclver CR. An overview of boeing flywheel energy storage systems with high-temperature superconducting bearings. J Supercond Sci Tech 2010.

29. Anonymous. Vyconenergy. Available at: http://www.vycone nergy.com. Accessed: Oct 2014.

30. Bender D, Blackman K, Borneo D, Ellison M, Eyer J, Greenberger J, Hernández J, Lazarewicz M, Nourai A. Electrical energy storage demonstration projects; SAND2014-17245 0, Aug 2014.

31. Eckroad S. Flywheels for electric utility energy storage. TR108889, EPRI Palo Alto, California, Final Report, Dec 1999.

32. Schoenung SM, Hassenzahl WV. Long- vs. short-term energy storage -technologies analysis -a life-cycle cost study- a study for the DOE energy storage systems program. Sandia National Laboratories, Albuquerque, New Mexico, SAND2003-2783, Aug 2003.

33. Anaya-Lara O, Jenkins N, Ekanayake J, Cartwright P, Hughes M. Wind energy generation modelling and control. Chichester, West Sussex, P019 8SQ, United Kingdom: John Wiley \& Sons Ltd, 2009.

34. Vidyanandan KV, Senroy N. Primary frequency regulation by deloaded wind turbines using variable droop. IEEE Trans Power Syst 2013;28:837, 846.

35. Roy S, Malik OP, Hope GS. A low order computer model for adaptive speed control of diesel driven power-plants, Conference Record of the 1991 IEEE Industry Applications Society Annual Meeting, 1991. 1636, 1642 2, 28 Sept 1991-4 Oct 1991.

36. Ghosh S, Senroy N. Electromechanical dynamics of controlled variable-speed wind turbines. IEEE Syst J 2013;9:639-646 June 2015. 
37. Slootweg JG. Wind power modelling and impact on power systems dynamics Ph.D. dissertation, Delft Univ. Technol., Delft, The Netherlands, 2003.

38. Akhmatov V. Variable-speed wind turbines with doubly-fed induction generators, part I: modelling in dynamic simulation tools. WINEN 2002;26:85-108.
39. Wang P, Billinton R. Reliability benefit analysis of adding WTG to a distribution system. IEEE Trans Energy Conv 2001;16:134-39.

40. Hayes RJ, Kajs JP, Thompson RC, Beno JH. Design and testing of a flywheel battery for a transit bus, 1999 SAE International Congress and Exposition, Detroit, MI, March 1-4, 1999. 